\title{
Les phénotypes inattendus des souris déficientes en glycoprotéines $P$, produits des gènes $\mathrm{mdr}$
}

Le phénotype de résistance multiple aux médicaments cytolytiques (multidrug resistance) peut être lié à l'hyperexpression ou à l'amplification de gènes dénommés $M I R l$, chez l'homme, et mdrla et $m d r l b$, chez la souris [1]. Par ailleurs, un gène très voisin a été trouvé dans les deux espèces, dénommé, respectivement, $M D R 3$ et $m d r 2$; ce gène ne semble pas conférer la résistance multiple aux médicaments anticancéreux. Les produits des gènes $m d r$ sont des glycoprotéines appartenant à la famille des transporteurs possédant une cassette de fixation de l'ATP à laquelle appartient également le produit du gène de la mucoviscidose. La fonction naturelle de telles glycoprotéines n'étant probablement pas d'expulser les produits anticancéreux hors des cellules, de nombreuses équipes ont recherché ce que pouvait être leur rôle réel. C'est ainsi que l'on a proposé que ces glycoprotéines $\mathrm{P}$ soient des canaux à chlore contrôlés par le volume cellulaire [2] ou bien des canaux à ATP [3]. Plusieurs équipes néerlandaises associées, dirigées par Berns et Borst (Amsterdam) ont choisi, pour résoudre ce problème, de créer, par recombinaison homologue, des lignées de souris transgéniques dont, soit les deux gènes $m d r 2$ [4], soit les deux gènes mdrla [5], ont été inactivés. Les animaux $m d r 2 \%$ développent une maladie hépatique caractérisée par une cholestase avec ictère, des anomalies histologiques des hépatocytes et des infiltrats inflammatoires. Cette maladie semble causée par l'impossibilité pour le foie de sécréter des phospholipides dans la bile. Que le produit du gène $m d r 2$ joue un rôle essentiel dans l'excrétion biliaire des phospholipides est en accord avec la localisation hépato-biliaire de cette protéine. Les souris mdrla\% semblaient, quant à elles, initialement normales et leur phénotype fut révélé tout à fait par hasard. Les souris résultant du croisement entre deux hétérozygotes pour l'invalidation du gène mdrla furent traitées par l'ivermectine, un médicament acaricide et antihelmintique pour une gale. La pulvérisation de ce produit est habituellement très bien tolérée. Or, elle entraîna ici la mort d'une partie des animaux qui se révélèrent être des homozygotes pour l'invalidation du gène mdrla. Cette mortalité, précédée de signes neurologiques, est selon toute évidence due à la neurotoxicité de l'antiparasitaire qui s'accumule pratiquement cent fois plus dans le cerveau des souris déficientes que dans celui de souris normales ou hétérozygotes. Le produit du gène mdrla est particulièrement abondant au niveau des cellules endothéliales de la barrière hématoencéphalique où il est probablement capable, chez des animaux normaux, de détoxifier les tissus nerveux du produit qui pourrait s'y accumuler. Par ailleurs, ces animaux sont également particulièrement sensibles à un anticancéreux comme la vinblastine. Des produits sont aujourd'hui testés en phase I et II quant à leur capacité d'inhiber les produits des gènes $M D R$ et donc d'inverser les phénotypes de résistance aux anticancéreux. Les résultats rapportés par Schinkel et al. suggèrent que ces traitements pourraient comporter un risque, celui de considérablement sensibiliser les malades à l'effet neurotoxique des médicaments ou de tout autre produit administré de façon intercurrente. Il faut remarquer que si ces travaux semblent bien déboucher sur l'élucidation du rôle physiologique de la protéine Mdr2, qui serait un transporteur de phospholipides, ils n'indiquent pas, en revanche, ce que sont les substrats endogènes de la protéine Mdrla. Reste également à déterminer le phénotype particulier causé par l'invalidation du gène $m d r l b$, et surtout par l'invalidation combinée de $m d r l a$ et mdrlb. Ces deux gènes étant liés, cela nécessitera de réaliser une recombinaison homologue conjointe des deux loci dans les mêmes cellules ES.

A.K.

1. Marie JP. Le phénomène de résistance multiple aux anticancéreux : les gènes $M D R$ et la $\mathrm{P}$ gp. médecine/sciences $1990 ; 6$ : 443-52.

2. Valverde RA, Diaz M, Sepúlveda FV' et al. Volume-regulated chloride channels associated with the human multidrug-resistance P-glycoprotein. Nature $1992 ; 355: 830-3$.

3. Abraham EH, Prat AG, Gerweck L, et al. The multidrug-resistance (mdrl) gene product functions as an ATP channel. Proc Natl Acad Si USA $1993 ; 90: 312-6$.

4. Smit [JM, Schinkel AH, Oude Elf erink RPJ, et al. Homozygous disruption of the murine $m d r 2$ P.glycoprotein gene leads to a complete absence of phospholipid from bile and to liver disease. Cell 1993 ; 75 : 451-62.

5. Schinkel AH, Smit JJM, van Tellingen O, et al Disruption of the mouse mdrla P-glycoprotein gene leads to a deficiency in the blood-brain barrier and to increased sensitivity to drugs. Cell $1994: 77 \cdot 491-502$ 